\title{
The spatial-temporal dynamics in job accessibility by car in the Netherlands during the crisis
}

\author{
Borja Moya-Gómez $^{\mathrm{a}}$ (1) and Karst T. Geurs ${ }^{\mathrm{b}}$ (1)
}

\begin{abstract}
This paper analyzes the changes in spatial-temporal job accessibility by car in the Netherlands during the economic crisis (2009-14). It also assesses which component change is the most determinant in accessibility changes per municipality and part of the day. The paper shows that changes in job distribution reduced accessibility in almost the entire country, except around Amsterdam. Improvements in the road network capacity increased accessibility in the central provinces, particularly during peak hours. In summary, the values of job accessibility by car in the Netherlands became more transport dependent, except in the Amsterdam region.
\end{abstract}

KEYWORDS

job accessibility; dynamic accessibility; traffic congestion; spatial-temporal patterns; economic crisis; the Netherlands

JEL J60, R14

HISTORY Received 28 September 2017; in revised form 13 October 2018

\section{INTRODUCTION}

Accessibility is a key concept in both transport and spatial planning/studies. Early definitions include 'the potential of opportunities for interaction' (Hansen, 1959, p. 73) and 'the ease with which activities can be reached, given a location, using a specific transport system' (Morris, Dumble, \& Wigan, 1979, p. 91). Many different accessibility indicators have been developed. They typically focus on one or more of the four components of accessibility: (1) the land-use component, reflecting the amount, quality and spatial distribution of opportunities; (2) the transportation component, describing the disutility of travel in terms of time, cost and effort; (3) the temporal component, reflecting the temporal constraints and variability; and (4) the individual component, reflecting the needs and abilities of individuals (Geurs \& Van Wee, 2004). The choice and operationalization of an accessibility measure depends on the object and aim of each study (Bruinsma \& Rietveld, 1998; Curl, Nelson, \& Anable, 2011; Geurs \& Ritsema van Eck, 2001; Handy \& Niemeier, 1997; Páez, Scott, \& Morency, 2012; Reggiani, 1998).

The analysis of job accessibility is essential since jobs are usually the main source of family incomes and job accessibility can be a decisive aspect for moving or commuting (Eliasson, Lindgren, \& Westerlund, 2003). Changes in the quantity, quality and variety of job accessibility might trigger location decisions for households. Moreover, studies in the Netherlands show that changes in accessibility are also significantly affected firm relocations, though their effects vary over sectors and firmlevel attributes are more important in relocation decisions (De Bok \& Van Oort, 2011). Labour markets and their evolution are 'determined by location decisions by firms and households in combination with decisions concerning commuting' (Johansson, Klaesson, \& Olsson, 2002); this may be considered as the result between socioeconomic actors, in a complex intra-/inter-spatial cooperation (Reggiani, Bucci, Russo, Haas, \& Nijkamp, 2011). Changes in the spatial distribution of workers and job positions might not be synchronized, and economic crises can increase spatial mismatches and make them more noticeable. Analysis of spatial distribution of job accessibility values and their evolution may uncover some income vulnerabilities related to the high proportion of individual incomes due to the lack of any alternative or of facing excessive commuting trips (Bocarejo \& Oviedo, 2012; Dodson \& Sipe, 2008).

\footnotetext{
CONTACT

${ }^{a}$ (Corresponding author) bmoyagomez@ucm.es

Transport, Infrastructure, and Territory Research Group (tGIS), Geography Department, Faculty of Geography and History, Universidad Complutense de Madrid (UCM), Madrid, Spain.

${ }^{\mathbf{b}}$ k.t.geurs@utwente.nl

Centre for Transport Studies (CTS), Faculty of Engineering Technology, University of Twente, Enschede, the Netherlands.

(-) Supplemental data for this article can be accessed at https://doi.org/10.1080/00343404.2018.1538554.
} 
A high proportion of workers have similar schedules and bring the transport networks to their limits. Congestion can become a recurrent temporal obstacle for reaching jobs. Congestion has economic consequences but also affects workers directly (Sweet, 2011), and it can influence job searching processes and its derivate reactions, such as moving house or commuting. Congestion is a purely dynamic phenomenon. Traditional static accessibility models do not capture the temporal dynamics in delays and congestion (Kwan, 2013; Weber \& Kwan, 2002). Moreover, static accessibility models cannot deal with dynamic traffic management strategies, which nowadays are an important part of increasing road infrastructure capacity or rescheduling education/job schedules, which is of interest to smooth journey flow values. The growing abundance of detailed spatial data and (almost) real-time transport data sets provides opportunities for improving accessibility modelling and assessing a wide scope of dynamic consequences covered.

The aim of this paper is to assess the spatial-temporal dynamics in job accessibility by car in the Netherlands during the period of economic crisis (2009-14), distinguishing between the effects of job activity changes, road-network capacity increases and congestion levels.

The paper is structured as follows. The next section describes spatial-economic developments, road network and car mobility changes in the Netherlands between 2009 and 2014. The third section explains the methodology of this analysis. The fourth section introduces the data. Section five analyzes of the results. The final section draws conclusions and describes directions for further research.

\section{THE NETHERLANDS BETWEEN 2009 AND 2014}

The world economic crisis between 2009 and 2014 led to change in the Netherlands. The number of job positions peaked before the economic crisis in 2009 ( 8.2 million), and dropped to a local minimum in 2014, below 8 million job positions (Stichting LISA, 2016). In the same period, the active population ${ }^{1}$ increased from 8.7 million to almost 8.9 million people. As a result, the unemployment rate rose from $4.4 \%$ to $7.4 \%$ (Statistics Netherlands, 2017a). The Netherlands has slowly recovered the number of job positions from the economic crisis since 2015, with unemployment rates at the end of 2017 just below pre-crisis levels (Statistics Netherlands, 2017b).

\section{Active population and job-distribution changes}

Active population and job positions are not evenly distributed in the Netherlands, and the effects of the crisis were also not evenly distributed. Figure 1 shows the concentration patterns for population and jobs by municipalities ${ }^{2}$ between 2009 and 2014. Both variables had similar geographical distribution. The highest population/job position density area of the Netherlands is the Randstad area (Amsterdam, Rotterdam, The Hague and Utrecht, and several middle-sized cities). Other concentrations are found in Noord-Brabant, Arnhem-Nijmegen, Zuid-Limburg, Twente, and Groningen. During the crisis years, the active population increased in almost all main cities in the Netherlands and their outskirts, with the strongest increase in and around the main cities in the Randstad area. Job density growth is found in only a few cities and their near surroundings around Amsterdam and Utrecht, Arnhem, and Eindhoven. In the same period, a substantial part of the country showed a decrease in the number of available jobs. The south-west of the Randstad area, some cities in the Noord-Brabant and Zuid-Limburg lost up to $10 \%$ of job positions. Those values show changes in the spatial structure of the distribution of job positions and new mismatches with the active population.

\section{Road network investments and car mobility}

Between September $2011^{3}$ and September 2014, almost $300 \mathrm{~km}$ of major roads were improved, for example, more lanes, increasing intersection capacity and urban bypasses. There also were $160 \mathrm{~km}$ of new major roads, most of them road detours. Regarding dynamic improvements, the length of the dynamic-opening lanes, shoulder running lanes (spitsstroken) and plus lanes (plusstroken) grew by $75 \mathrm{~km}$. Figure 2 shows where the road network was improved: $33 \%$ of these investments in kilometres were located between Eindhoven and Utrecht, on the A2 motorway, and in Amsterdam's and Utrecht's surroundings. Other measures were applied during this period: variable maximum speed, dynamic traffic information and an off-peak higher maximum speed (130 $\mathrm{km} / \mathrm{h}$ ) in some sections. TomTom data also show some other changes on other roads, especially in urban zones, such as changing directions and new car-free areas.

As Table 1 shows, mobility by car changed. Total kilometres travelled by car increased by $2.2 \%$, but the kilometres travelled by lorries and vans dropped by $19.7 \%$ and $6.4 \%$, respectively. During peak hours, traffic volume increased, but congestion severity and the time lost in traffic jams decreased. On the other hand, the average carcommute distance increased by $7 \%$ in the whole country between 2010 and 2014, especially in the Randstad and Northern provinces, but the commute time remained stable (Statistics Netherlands, 2017c).

\section{METHODOLOGY FOR COMPARING DYNAMIC DAILY ACCESSIBILITY PATTERNS}

\section{A dynamic accessibility approach}

A modification of the well-known potential accessibility (Hansen, 1959) is used partially to introduce temporal dynamics in job accessibility. Potential accessibility counts how many weighted opportunities every zone/individual may reach. The weight of every destination from each origin depends on the impedance of the relation (Deboosere, Levinson, \& El-Geneidy, 2017). 
Item
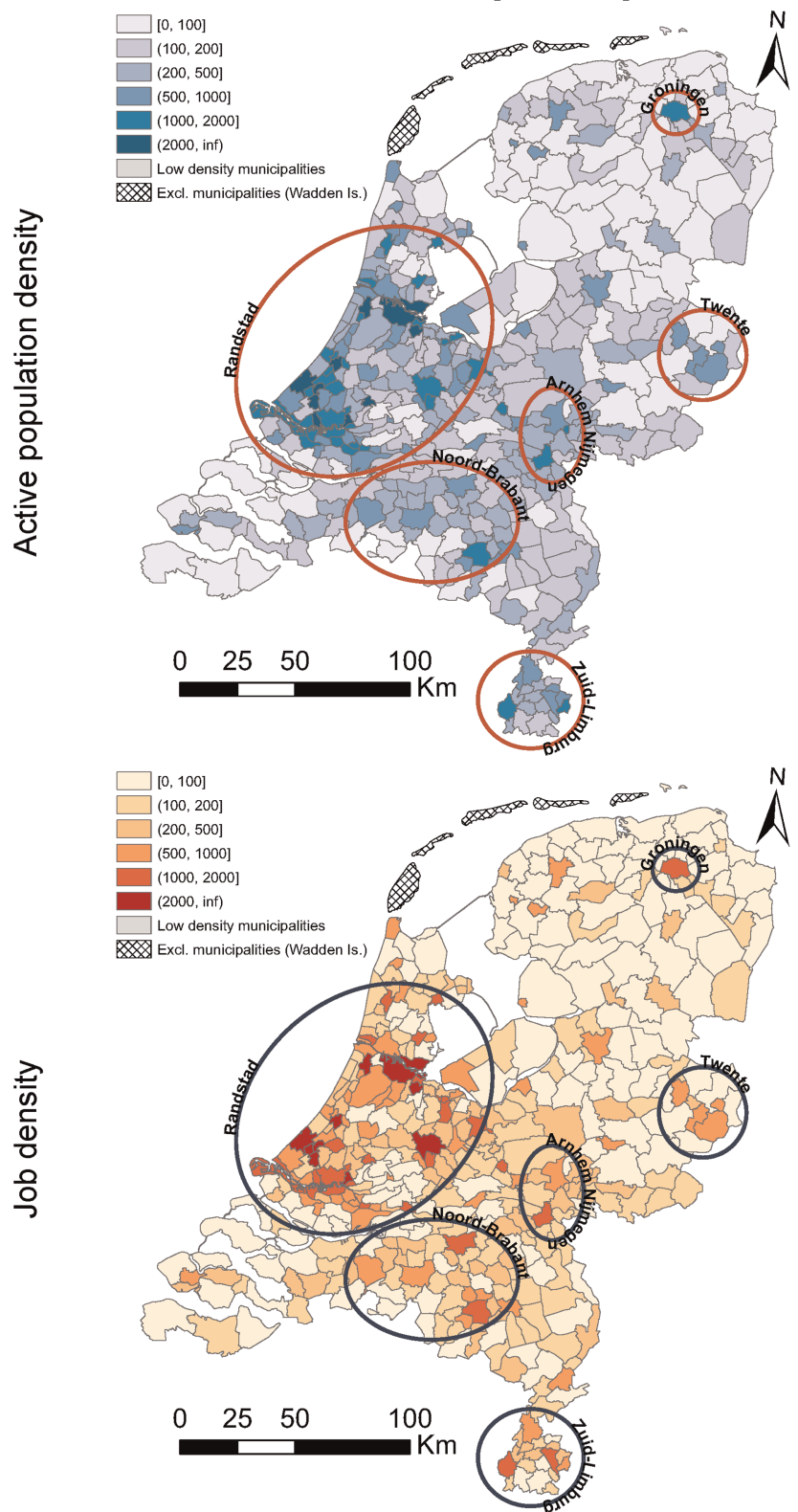

Relative Difference (2014 values / 2009 values)
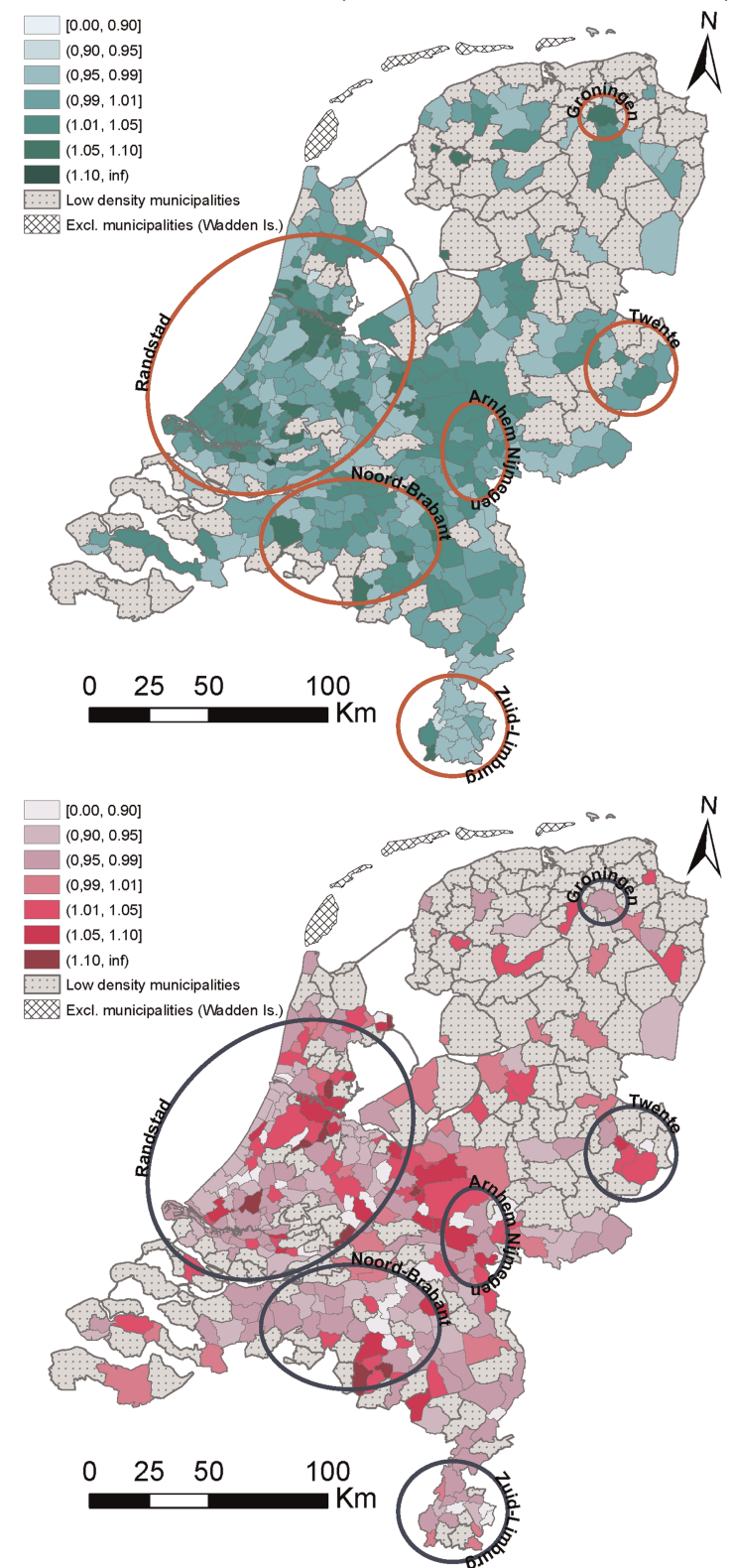

Figure 1. Population and job position density distribution in 2009 and relative changes to 2014 . Low-density municipalities have $\leq 100$ item $/ \mathrm{km}^{2}$.

Note: The coordinate projection system of maps is Lambert Azimuthal Equal Area - ERTS89. Colour ramps of polygon maps are from ColorBrewer2 (Brewer \& Harrower, 2013).

Temporal dynamics are partially introduced by using dynamic impedances (equation 1), that is, impedance depends on when links are used on every route and its temporal variation in impedance across the day. Since travel speeds continuously change due to congestion, each origin-destination relationship was calculated several times over a day to approximate the dynamic variation. These impedances are calculated as travel times by the hierarchical first-in-first-out (FIFO) dynamic shortest-path algorithm in ArcGIS 10.3: waiting is not an option to arrive earlier at any destination (Dean, 2004). The opportunity component is considered as a set of constant values to unmask the direct effects of congestion variations throughout the day. This dynamic accessibility approach follows Weibull's
(1976) accessibility axioms.

$$
\begin{aligned}
& a_{i}^{t}=\sum_{j \in N} d_{j} \cdot f\left(c_{i j}^{t}\right), \forall i \in N, t \in T \\
& \text { s.t.: } \\
& c_{i j}^{t}=\sum_{m \in M} \sum_{e \in E} \alpha_{e i j}^{t m} \cdot c_{e}^{m}, \forall i \in N, j \in N, t \in T \\
& \text { FIFO condition - arrival time: } t_{k}+c_{k l}^{t} \leq(t+1)_{k}+c_{k l}^{t+1}
\end{aligned}
$$

where $a_{i}^{t}$ is the potential accessibility of origin $i$, departing at time $t, d_{j}$ is the number of opportunities of destination $j$; $f\left(c_{i j}^{t}\right)$ is the impedance decay function that weights 

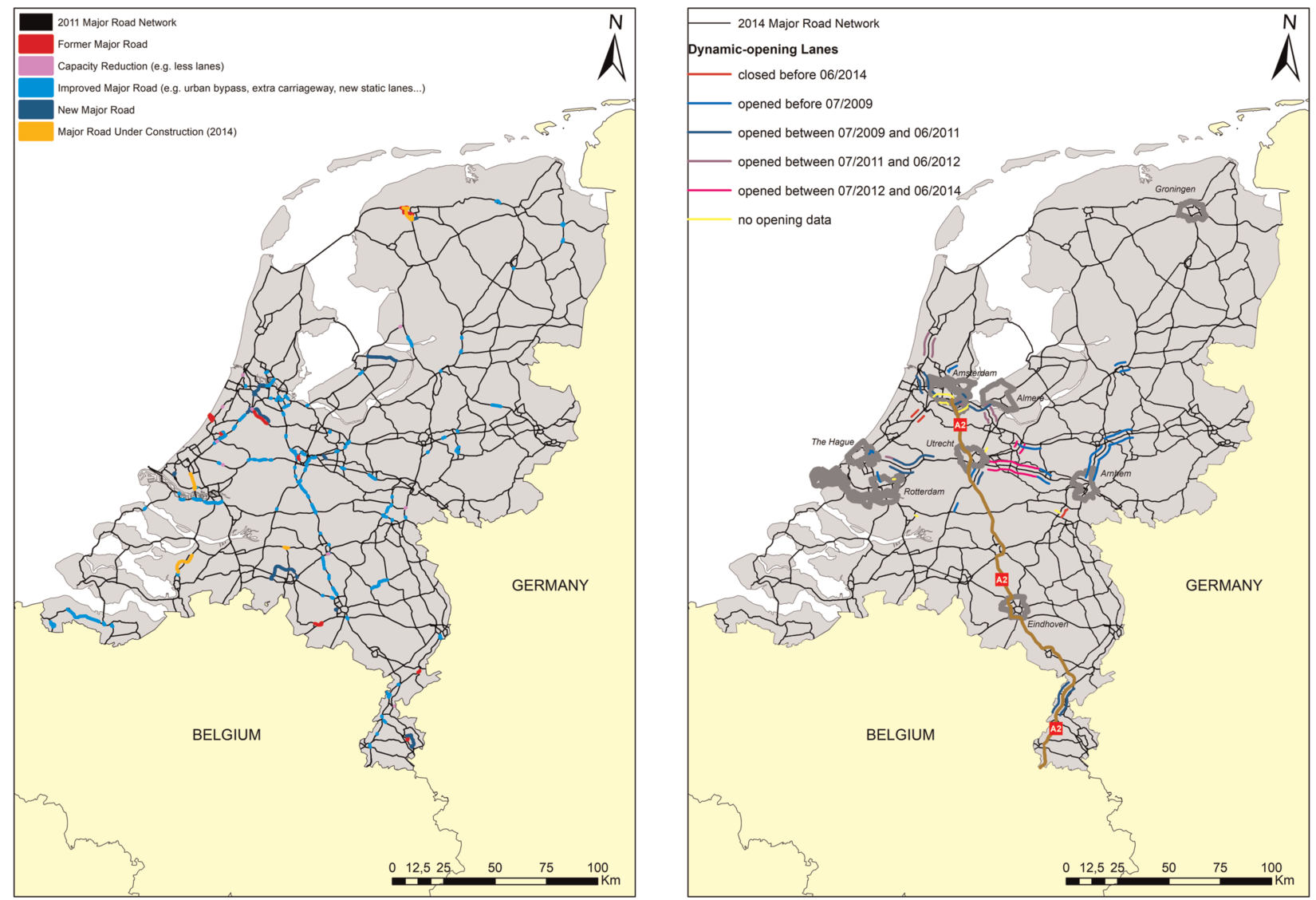

Figure 2. Changes in Dutch major road network between 2011 and 2014.

Sources: TomTom and Dutch government.

opportunities by impedance; ${ }^{4} c_{i j}^{t}$ is the impedance when travelling from origin $i$ to destination $j$ by the dynamic shortest path, departing at time $t ; \alpha_{e i j}^{t m}$ is the dummy variable that indicates whether network link $e$ at time $m$ is used for the trip between origin $i$ and destination $j$ departed at time $t ; c_{e}^{m}$ is the expected impedance of network link $e$ at time $m ; t_{k}$ is departing time $t$ in node $k ; N$ represents all the zones included in the calculation area; $T$ is the set of time of departing trips; and $M$ is all possible time instants within the study.

Table 1. Congestion values and mobility changes in the Netherlands between 2009 and 2014

\begin{tabular}{|c|c|c|c|c|}
\hline Item & Unit & 2009 & 2011 & 2014 \\
\hline Total kilometres travelled by motor vehicles ${ }^{a}$ & million km & $127,297.3$ & $128,286.0$ & $127,680.2$ \\
\hline Total kilometres travelled by private cars $^{a}$ & million km & $101,514.0$ & $102,956.4$ & $103,699.1$ \\
\hline Total kilometres travelled by vans ${ }^{a}$ & million km & $17,407.0$ & $17,056.1$ & $16,295.5$ \\
\hline Total kilometres travelled by lorries ${ }^{a}$ & million $\mathrm{km}$ & 2669.8 & 2489.8 & 2142.6 \\
\hline Average travelled kilometres at 08:00 hours (morning peak) & million $\mathrm{km}$ & 1.21 & 1.27 & 1.37 \\
\hline Average travelled kilometres at 17:00 hours (afternoon peak) & million $\mathrm{km}$ & 1.24 & 1.33 & 1.43 \\
\hline Total time lost on major routes $(\mathrm{MR})^{\mathrm{b}}$ & million hours & 61.9 & 53.9 & 45.4 \\
\hline Total time lost in traffic jams on $\mathrm{MR}^{\mathrm{b}}$ & million hours & 43.0 & 35.9 & 28.5 \\
\hline Congestion severity ${ }^{b}$ & year $2000=100$ & 130 & 105 & 80 \\
\hline Average length of the most congested hour during the morning peak & $\mathrm{km}$ & n.d. & 110 & 95 \\
\hline $\begin{array}{l}\text { Average length of the most congested hour during the afternoon } \\
\text { peak }^{\mathrm{b}}\end{array}$ & $\mathrm{km}$ & n.d. & 142 & 130 \\
\hline
\end{tabular}

Note: n.d., Not determined.

Sources: ${ }^{\text {a }}$ Statistics Netherlands (2017d).

${ }^{\mathrm{b}}$ Ministerie van Infrastructuur en Milieu (2015). 
The results of equation (1) for every zone might be aggregated into some higher ranking territorial unit and part of the day, by weights (equation 2):

$$
a_{l p}=\frac{\sum_{i \in N} \beta_{i l} \cdot o_{i} \cdot \frac{\sum_{t \in P} a_{i}^{t}}{|t \in p|}}{\sum_{i \in N} \beta_{i l} \cdot o_{i}}, \forall p \in P, l \in L
$$

where $a_{l p}$ is the weighted mean accessibility of higher rank territorial unit $l$ for period $p ; \beta_{i l}$ is a dummy variable, which indicates if zone $i$ belongs to higher rank territorial unit $l ; o_{i}$ is the weight of zone $i ; l$ is each higher rank territorial unit in the $L$ set of higher rank territorial units; and $p$ is a subset of contiguous departing times at $T$ of each study period in the $P$ set of the parts of the day.

\section{The comparison framework of the daily} accessibility patterns between situations

Changes in accessibility are a consequence of a myriad of changes, such as the redistribution of opportunities, changes in transport services or infrastructures and their efficiency, and even individual changes in preferences (Haugen, Holm, Strömgren, Vilhelmson, \& Westin, 2012). In this study, four situations were calculated to compare the effects of the component changes on accessibility, excluding possible interactions between the components as implemented in a similar approach by Geurs and Ritsema van Eck (2003) and Levinson, Marion, Owen, and Cui (2017) (equation 3):

$$
\begin{aligned}
& \text { (Reference year: RY) } A^{R Y}=g\left(D^{R Y}, f\left(\theta, C^{R Y}\right)\right) \\
& \text { (Land uses changes: LC) } A^{L C}=g\left(D^{F Y}, f\left(\theta, C^{R Y}\right)\right) \\
& \text { (Transportation changes: TC) } A^{T C}=g\left(D^{R Y}, f\left(\theta, C^{F Y}\right)\right) \\
& \text { (Final year: FY) } A^{F Y}=g\left(D^{F Y}, f\left(\theta, C^{F Y}\right)\right)
\end{aligned}
$$

where $A$ is the data set of accessibility; $g(\cdot)$ is an accessibility measurement function; $D$ is the land-use component; $C$ is the transport-impedance vector; $f(\theta, C)$ is the impedance function; and $\Theta$ are the parameters of the impedance-decay function. The superscripts indicate which data set and calculus conditions are used.

Three comparisons were used to understand the effects of each component in the very same part of the day, based on the basis situation (equation 4):

$$
\begin{aligned}
& \text { Land uses change effects }(\mathrm{a})=\frac{A^{L C}}{A^{R Y}} \\
& \text { Transportation change effects }(\mathrm{b})=\frac{A^{T C}}{A^{R Y}} \\
& \text { Combined effects }(\mathrm{c})=\frac{A^{F Y}}{A^{R Y}}
\end{aligned}
$$

The situations assume that the impedance-decay function parameters are invariable, and the dynamic transport efficiency only depended on infrastructure, that is, spatial distribution changes did not change traffic flows.

\section{DATA}

\section{Land-use data: the spatial-temporal data of job position distribution}

The source of job position distribution data for 2009 and 2014 is the Landelijk InformatieSysteem van Arbeidsplaatsen (National Job Information System) (LISA) data (Stichting LISA, 2016). LISA data include the number of job positions and the address, among others, for each business in the Netherlands.

The LISA data were summarized to the 2010 version of post code four-digit (PC4) zones. There were 4010 PC4 zones in the Netherlands, excluding zones entirely within islands and post boxes. The location of PC4's centroid for origin-destination impedance matrix is the populationweighted centre of population mass, from the $100 \times 100 \mathrm{~m}$ square data set (Statistics Netherlands, 2015) for residential zones, ${ }^{5}$ and the geometrical centroid otherwise.

The LISA data set is the only data set available in the Netherlands comprising exact job positions at a national level. Although the data set might in some cases incorrectly allocate job positions of some business to a unique location, the LISA data are considered a reliable data source to examine changes in the spatial distribution of jobs over time.

\section{Transport component: the road network and congestion}

The road networks in this study are sourced from September 2011 and September 2014 versions of two TomTom products. The Dutch road network is defined by TomTom Multinet. The main road network was used, that is, links in categories $0-6$ of the TomTom functional road classification (FRC) ${ }^{6}$ without ferry services. There are no disconnected links, and every zone is connected to all other zones in both directions. The second product is the historical speed profile (HSP). The speed profiles are made up of the speeds averaged every $5 \mathrm{~min}$ (TomTom, 2013) from the previous 24 months (Table 2) from more than 1000 observations every $5 \mathrm{~min}$ reported by TomTom devices. These data are free of outlier situations, for example, short maintenance works, accidents or bad weather conditions. There are some differences in speed profile definitions between versions, but no unique possible relationship between both profile sets. However, the most probable relationships were quite similar in shape and intensity.

\section{Aggregated individual component: the impedance-decay function}

A unique impedance-decay function was calibrated using the car commuter journey records from the 2010 national travel survey (Statistics Netherlands, 2011). These records show that $98 \%$ of car commuter journeys took fewer than $90 \mathrm{~min}$, and the reported times were usually divisible by five (Martínez \& Viegas, 2013). As a result, the data for calibrating the impedance function are truncated at 90 $\mathrm{min}$, and values were gathered in groups of $5 \mathrm{~min}$. 
Table 2. Summary of the 2011 and 2014 versions of TomTom data.

\begin{tabular}{lcc}
\hline & September 2011 version & September 2014 version \\
\hline Data collection period & July 2009-June 2011 & July 2012-June 2014 \\
Predefined profiles & 98 & 293 \\
Not free flow speed between (hours) & $04: 30-21: 20$ & $04: 00-21: 50$ \\
\% km major road with HSP (FRC 0-2) & 99.32 & 99.27 \\
\% km secondary road with HSP (FRC 3) & 99.10 & 99.09 \\
\% km local road with HSP (FRC 4-6) & 55.33 & 56.68 \\
\% km study road network with HSP & 62.39 & 63.64 \\
\% km study road network/km total road network & $87,956 / 157,256$ & $88,009 / 163,042$ \\
Links study road network/links total road network & $738,274 / 1,460,427$ & $785,688 / 1,584,953$ \\
\hline
\end{tabular}

Note: FRC, functional road classification; HSP, historical speed profile.

Five well-known types of impedance-decay functions (Geurs \& Ritsema van Eck, 2001; Ingram, 1971; Östh, Lyhagen, \& Reggiani, 2016) were calibrated by R-Project: the inverse potential (Akaike information criterion $(\mathrm{AIC})=2.3377)$, negative exponential with one and two parameters (-34.7498 and -41.7925 respectably), Gaussian (-73.2205), and log-logistic $(-86.2425)$

The calibrated log-logistic is used in this paper because it had the lowest AIC (equation 5). ${ }^{7}$ It is an 'S'-shape curve function, where short distances give random commuting flows, and long distances are governed by a minimum cost principle (Thorsen, Ubøe, \& Nævdal, 1999):

$$
\begin{aligned}
& f\left(c_{i j}^{t}\right)=\frac{1}{1+e^{\theta_{2} \cdot\left(c_{i j}^{t}\right)^{\theta_{1}}}}, \text { if } c_{i j}^{t}<90 \mathrm{~min} \\
& f\left(c_{i j}^{t}\right)=0, \text { if } c_{i j}^{t} \geq 90 \mathrm{~min} \\
& \theta_{1}, \theta_{2} \in \mathcal{R} \text { impedance }- \text { decay parameters } \\
& \theta_{1}=2.767093027, \quad \theta_{2}=-8.789731669
\end{aligned}
$$

\section{THE IMPACT OF THE ECONOMIC CRISIS ON JOB ACCESSIBILITY}

This section discusses changes in the spatial-temporal distribution of job accessibility. The raw accessibility results, at the PC4 level, are drawn by obtaining impedance values every $15 \mathrm{~min}$. These results are aggregated by the active population, the same year as the spatial distribution of jobs, such as weight, into three parts of the day, and per municipality for Tuesdays and Thursdays ${ }^{8}$ to make the analysis: the morning peak (07:00-08:30 hours), midday (11:15-12:45 hours), and the afternoon peak (16:0017:30 hours), extreme hours included. In total, there were 426 municipalities, excluding municipalities entirely within the Wadden Islands.

The word 'accessibility' refers to job accessibility by car; 'job position' refers to the land-use component in this section.
Spatial-temporal distribution of job accessibility in the reference year (2009) Figure 3 shows the spatial distribution of accessibility in the reference year (2009). The results show almost concentric patterns with higher values near Amsterdam and Utrecht. Only remote areas have fewer than 250,000 weighted jobs $(w-j)$ in every part of the day. In the morning, the main cities had high accessibility, while the rest of the country experienced its worst values. At midday, accessibility was higher in the entire country. In the afternoon peak, accessibility was appreciably reduced in the main cities and their surrounding areas. This pattern seems logical, since traffic usually flows towards cities during the morning peak and flows away from cities in the afternoon. A high number of opportunities in the same area may have counteracted the effects of congestion. The lowest average job accessibility values in mornings are observed on Tuesdays $(721,493.50 \mathrm{w}-\mathrm{j})$ and in the afternoons on Thursdays $(715,400.11 \mathrm{w}-\mathrm{j})$.

\section{How did the road network and job distribution changes affect spatial-temporal job accessibility distribution?}

As Figures 4 and 5 show, changes in the spatial distribution of job accessibility had very different patterns depending on the changes of every accessibility component. Changes in the number and spatial distribution of jobs produce almost static effects. In general, the new job position distribution causes a decrement of up to $5 \%$ in the greater part of the country, and the worst results were in the southernmost part of the Netherlands, where heavy job losses were also found. The only exceptions were very concentrated in and around Amsterdam, where the strongest increase in jobs took place and job accessibility improvements are observed. Finally, municipalities in the area near the internal lagoon coast and along the corridor to the northeast, had no accessibility changes, since they maintained or barely increased their job densities. Notice that some zones with much higher job position density in 2014 compared with 2009 also deteriorated their accessibility because of their neighbours' losses; for instance, the increase in Eindhoven's, Utrecht's and Arnhem's surroundings was 


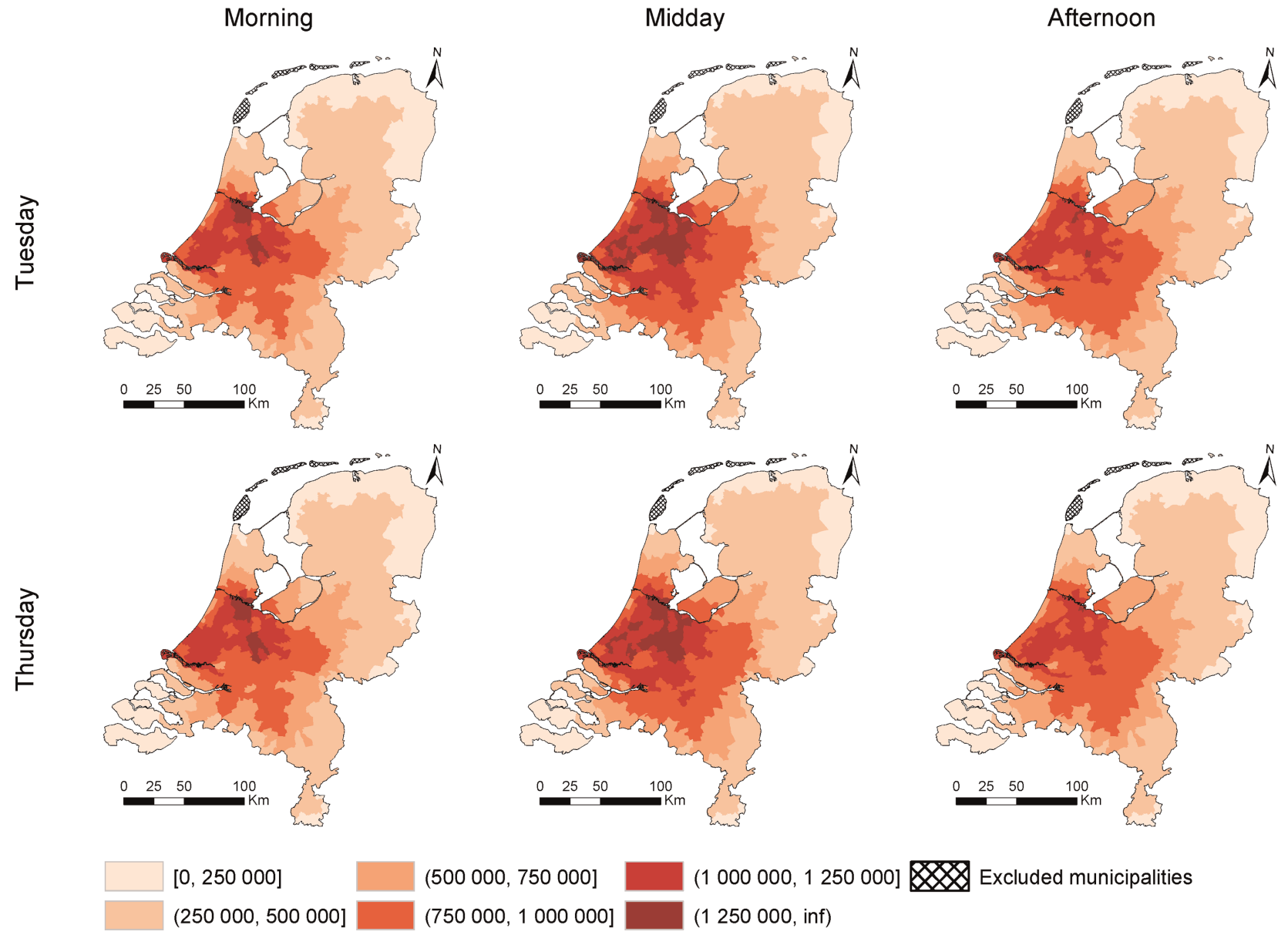

Figure 3. Spatial distribution of job accessibility in 2009 on Tuesdays and Thursdays (impedance-weighted jobs). Note: For readers of the printed version of the article, Figures 3-6 can be viewed in colour online; see https://doi.org/10.1080/ 00343404.2018.1538554

insufficient to compensate the job position losses in the other near locations.

Regarding transport changes, almost the entire country had a positive effect on both peaks, except in the Northern provinces. In the morning, Amsterdam's and Utrecht's outskirt municipalities had the greatest accessibility increments, up to $10 \%$, while accessibility increments in Amsterdam's and Utrecht were less than 5\%. The strongest and most spatially varying accessibility changes are found on Thursday mornings. On the contrary, the greatest increments in the afternoon were concentrated in Amsterdam and its southern area, where the most important road static investments had taken place. These results indicate that gains in new transport efficiency mainly occurred at peak hours. Improvement in off-peak hours was observed near road sections with static improvements, especially throughout the A2 motorway between Utrecht and Eindhoven. Finally, the lowest average accessibility occurred on Tuesday morning.

The combined-effect results show the municipalities that won/lost in accessibility. Municipalities with higher accessibility in 2014 than in 2009 were mainly placed in the central area of the country and near large road improvements during peaks, where higher direct-accessibility increases caused by transport changes were located.
Municipalities such as Almere during the mornings or Amsterdam in the afternoons also showed the positive additive effects of both component changes; they did not achieve these increases by changing only one component. However, in the other part of the country, total job accessibility is decreasing; travel time reductions do not compensate for the negative effect of job losses. At midday, the change in accessibility distribution is quite comparable with the effects of job-position changes, despite the slight decrease in the average. There were some notable exceptions, such as A2 motorway sections and Northern provinces. The lowest average job accessibility values were again on Tuesday morning $(731,584.80 \mathrm{w}-\mathrm{j})$ and on Thursday afternoon $(736,615.45 \mathrm{w}-\mathrm{j})$.

\section{What is the dominant change in spatial-} temporal accessibility distribution?

Finally, merely knowing which municipalities have won or lost in changes in job accessibility is insufficient to evaluate the results properly. The dominant change (transport changes or land-uses changes) must be uncovered to understand if the changes are appropriate, or might merely produce weak accessibility changes (Figure 6). The dominant effect is the partial effect with the most extreme change effect, if both partial changes have the same change 


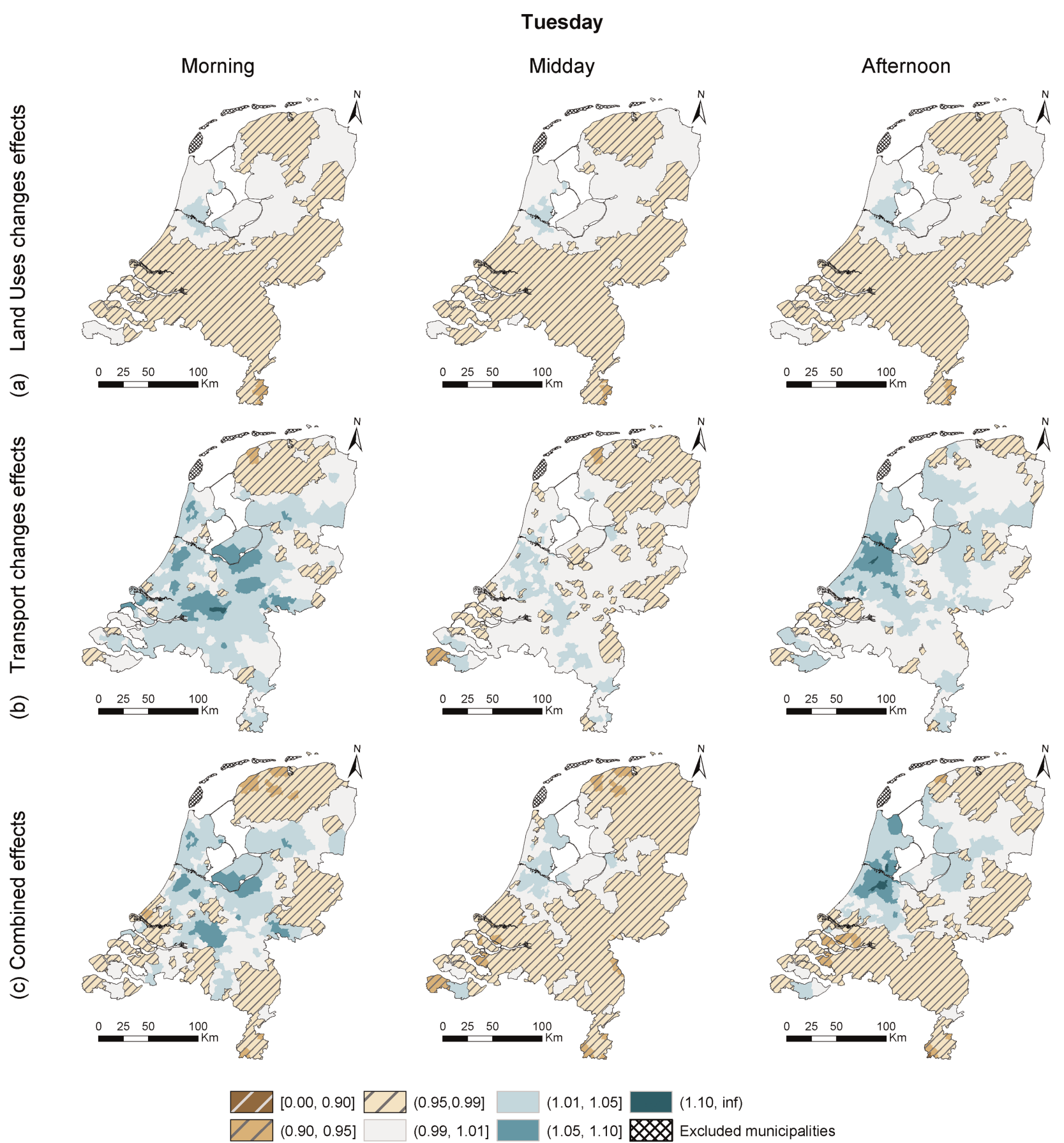

Figure 4. Spatial distribution of relative effects of job distribution changes, transport changes and combined effects in job accessibility on Tuesdays. Base $2009=1$.

direction. If each partial change has one change direction, the dominant change is the one whose effect has the same direction as the combined change.

- Municipalities in group 1 have a higher job accessibility in 2014 than in 2009: they received the positive additive effects of both changes:

- Subgroup $1 L+$. Job density increases are the main reason for increasing their accessibility. This subgroup appears in the morning and at midday in Amsterdam, and some of Amsterdam's surrounding municipalities.
- Subgroup 1T+. Municipalities in this subgroup mainly benefited from reducing travel time to job positions, but also benefited from increasing job density near them. This subgroup tended to appear in the afternoon in areas nearest Amsterdam. In the morning and at midday, outskirt municipalities in the Amsterdam region belong to this subgroup.

- Municipalities in group 2 only had the positive effects from new job position distribution. Transport-change effects are negative and counteract:

- Subgroup $2 L+$. This subgroup increased their accessibility because job densities near them increased. This 


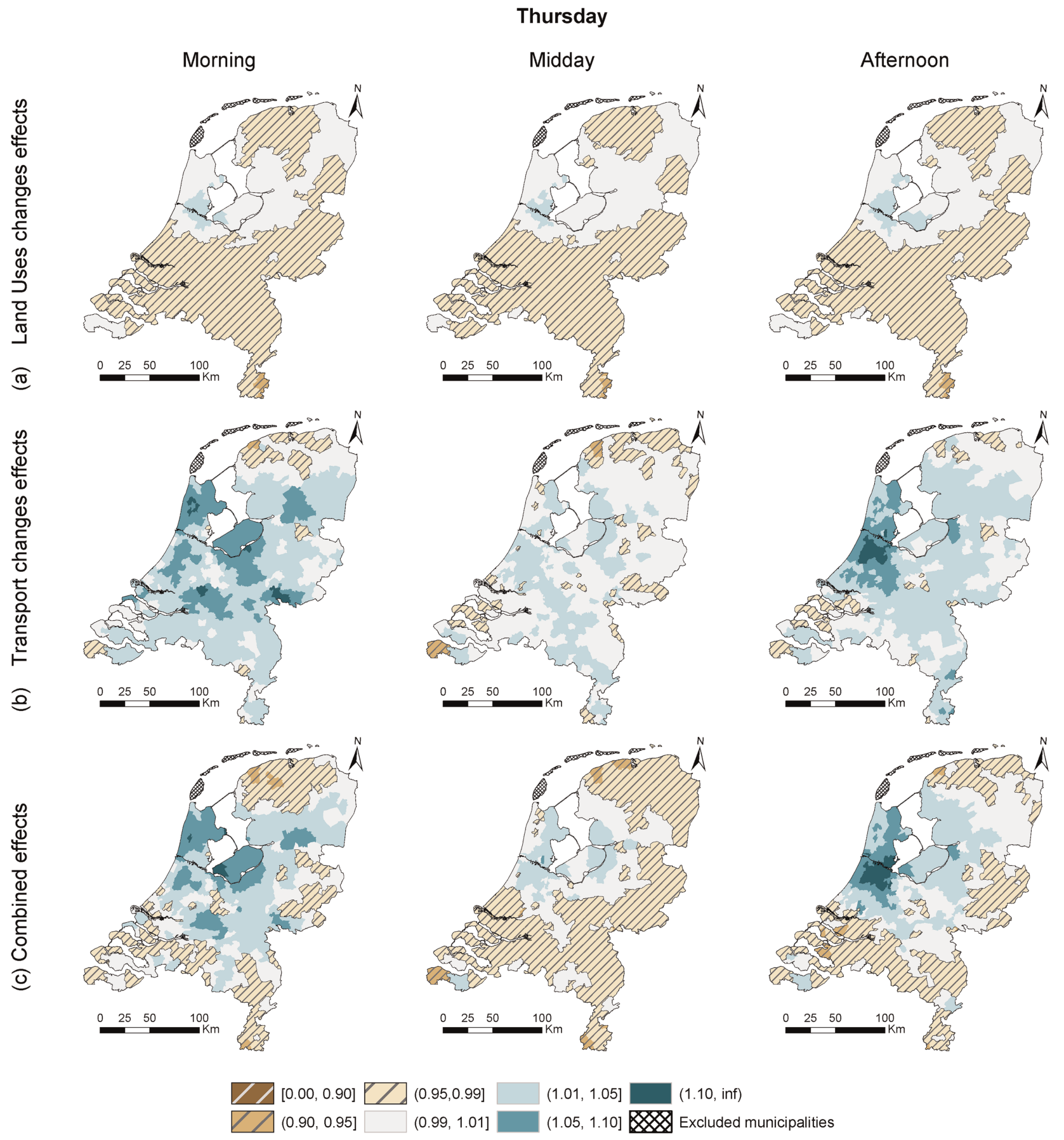

Figure 5. Spatial distribution of relative effects of job distribution changes, transport changes and combined effects in job accessibility on Thursdays. Base $2009=1$.

group appeared in some north-east outskirts of Amsterdam in the morning and at midday.

- Subgroup 2T-. This subgroup decreased their accessibility because travelling time conditions grew worse than in 2009, and increasing job position density in nearby areas was insufficient to counteract. Municipalities directly north of Amsterdam belong to this group at midday.

- In group 3, the municipalities lost accessibility because both components obtained worse accessibility:
- Subgroup 3L-. Municipalities of this subgroup experience a relatively significant decrease in jobs. Transport changes also decreased accessibility, but these losses are fewer. This subgroup mainly appeared in the most peripheral zones throughout the entire day, major cities in the south-western part of the Randstad area, and in Utrecht at midday. An exception is Utrecht: it lost accessibility despite it increased job position density, but its neighbouring areas did lose job density. 


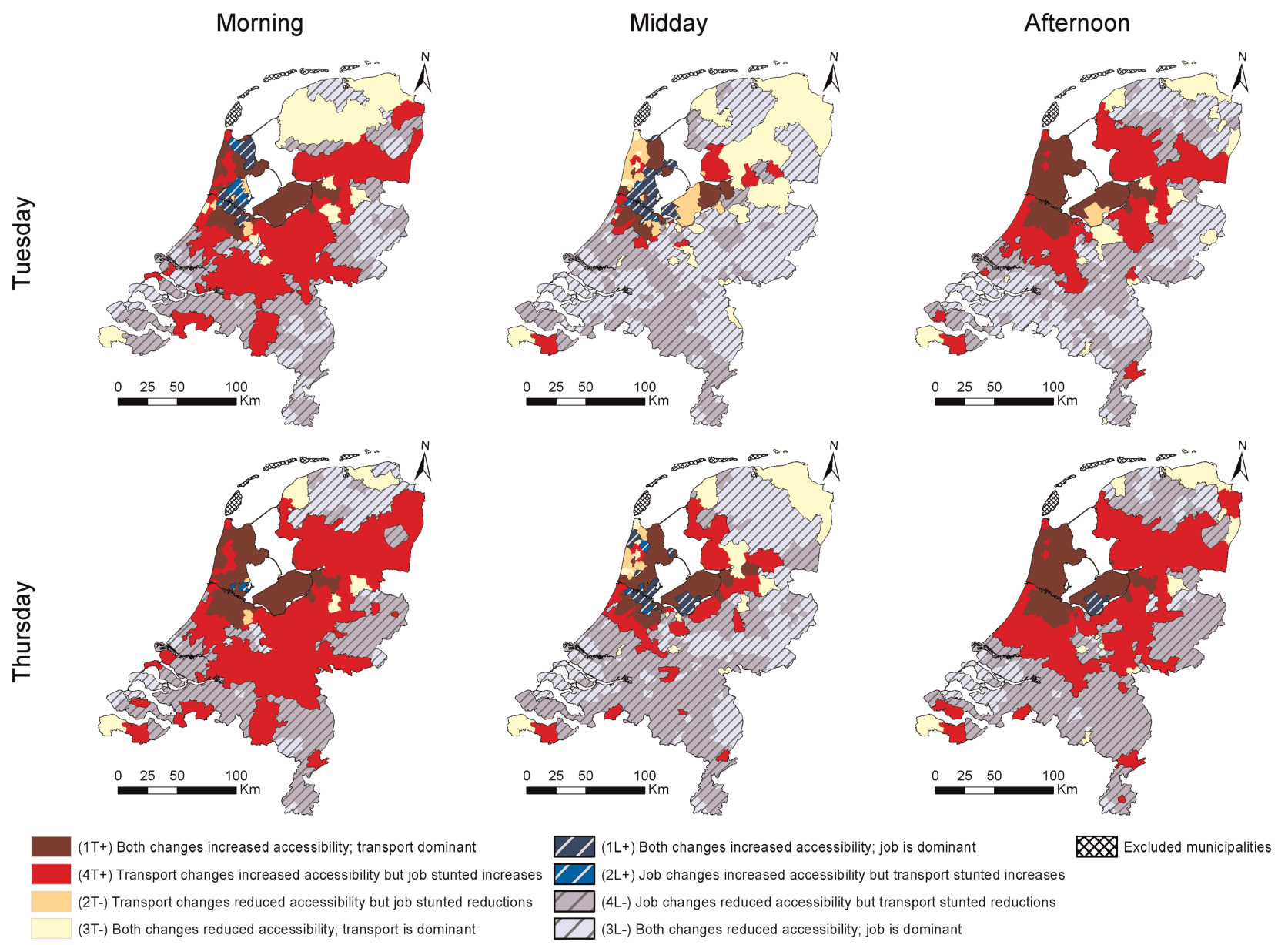

Figure 6. Spatial distribution of most determinant change and effects on Tuesdays and Thursdays.

- Subgroup 3T-. The accessibility of this subgroup reduced because of longer travel times to job positions. The loss of nearby job densities also reduced accessibility. The north-east municipalities mainly belonged to this subgroup in the morning and at midday, and only the remotest zones were in this subgroup during the afternoon peak.

- In group 4 , transport changes attempted to improve accessibility, but job positions changes counteracted:

- Subgroup $4 L-$ - Positive transport changes could not compensate for the negative effects of new job distribution and decreased accessibility. It appeared mainly between group $2 \mathrm{~L}$ and 3 municipalities, as the intermediate zone. This subgroup could be identified along the A2 corridor from Utrecht to the southern border on Tuesdays at midday. The south of Randstad also belonged to this group at both peaks.

- Subgroup 4T+. Municipalities 4T+ increased accessibility only because they could reduce travel times to job positions. However, accessibility improvements are weak because they may disappear with increasing congestion. This mainly occurs at municipalities near the major road to/from Amsterdam, with or without direct investments.

\section{DISCUSSION AND CONCLUSIONS}

This paper examined the spatial and temporal dynamics in potential job accessibility by car based on dynamic data from TomTom navigation devices in the Netherlands during the economic crisis between 2009 and 2014. To explain spatial-temporal variations in job accessibility, we examined the separate effects of the different factors of job accessibility change, that is, the effects of job density changes and road network improvements.

The spatial-temporal variation in job accessibility changes during the crisis years is considerable, resulting from complex interactions between job density changes, road infrastructure improvements, traffic flow, and dynamics in travel times (between days and times of the day). The overall conclusion is that job accesibility values became more transport dependent due to job position losses in almost the entire country, but their effects are very dependent on the dynamism of transport efficiency.

Despite the number of jobs decreasing during the economic crisis, the average job accessibility by car in peak hours increased, but only in one region of the Netherlands: the Amsterdam region benefited from the redistribution of the active population and jobs. As a consequence, job accessibility increased during the crisis years for all periods 
of the day the Amsterdam region. Other regions, such as Noord-Brabant, Groningen and the south of the Randstad, showed a decrease in job accessibility by car of up to $5 \%$. The positive changes in the transport component on job accessibility (higher average travel speeds) are insufficient to compensate losses in job positions in these areas.

The job-accessibility changes observed are uneven, and they mainly strengthened the central position of Amsterdam on the job market. However, these results may put pressure on this area, while other centralities are losing opportunities, but not an active population. These results also affect workers and job seekers: since jobs tend to concentrate where the land is scarce and expensive, people might be forced to decide whether to spend more money on housing or commute longer; this might create some job access barriers and have an impact on individual welfare.

Analyzing dynamic job accessibility, and the importance of changes, can thus be helpful in analyzing the effects of coordinated land-use and transport policies, to avoid or reduce negative effects, and in questioning if the current and the foreseeable accessibility are quite strong, or if they might strongly depend on short-term changes, for example, road congestion.

There are several directions that future research may take. First, research can focus on analyzing daily temporal, social inequalities in job accessibility changes, for example, how the economic crisis affected high- or low-skilled workers. Second, the effect of the economic crisis for workers relying on other transport modes is an interesting addition. Third, additional accessibility measures with competition effects can be considered, that is, accessibility also depends on how many users might reach every opportunity and compete to use it. Fourth, the full dynamic effect should also be studied by incorporating job-position schedules. Fifth, in the coming years a similar study can be undertaken for the period after the economic crisis, given that some changes need more time to become visible or to foster new situations, and to understand how daily changes in job accessibility can influence location decisions. Sixth, the effects of specific road project(s) on accessibility can be studied more accurately by using simulated traffic flows rather than only using observed data, as noted by Levine, Merlin, and Grengs (2017). A final direction for future research is to develop tools to conduct a joint analysis of spatial-temporal dynamics in accessibility measures, rather than splitting it into two parts as done in this paper.

\section{ACKNOWLEDGEMENTS}

The authors are very grateful to the peer reviewers, whose most welcome comments improved the clearness and utility of this paper.

\section{DISCLOSURE STATEMENT}

No potential conflict of interest was reported by the authors.

\section{FUNDING}

The work was supported by Ministerio de Economía y Competitividad (MINECO) [grant number TRA201127095 (SPILLTRANS)]; Ministerio de Economía y Competitividad (MINECO) and the European Regional Development Fund (ERDF) [grant number TRA201565283-R (DYNACCES)]; and Ministerio de Economía y Competitividad (MINECO) [grant numbers EEBB-I14-08424 and EEBB-I-15-09741 (Spanish National Sub-Programme for Mobility, 2013 and 2014 editions, within the National Programme for the Promotion of Talent and its Employability)].

\section{NOTES}

1. 'Active population includes both employed (employees and self-employed) and unemployed people, but not the economically inactive, such as pre-school children, school children, students and pensioners' (EUROSTAT, 2014).

2. Municipality delimitations in 2010 .

3. See the third section.

4. See the fourth section.

5. Residential zone: the jobs/population ratio is $<2.2$ (it is the 95 th percentile) and there are at least 0.5 jobs in services sector/inhabitant. The average for 2009 is 0.4932 jobs/ inhabitant.

6. FRC definitions: 0: Motorway, freeway, or other major road; 1: Major road less important than a motorway; 2: Other major road; 3: Secondary road; 4: Local connecting road; 5: Local road of high importance; 6: Local road; 7: Local road of minor importance; 8: Other roads.

7. The previous log-logistic impedance-decay function was rewritten in order to avoid some logarithm conceptual limitations.

8. These days were chosen because they had the worst job accessibility values at both peaks. For the figures for every weekday and a table with weighted averages at the Dutch level, see Appendix A in the supplemental data online.

\section{ORCID}

Borja Moya-Gómez (D) http://orcid.org/0000-0002-0520039X

Karst T. Geurs (D) http://orcid.org/0000-0003-0918-8903

\section{REFERENCES}

Bocarejo S., J. P., \& Oviedo H., D. R. (2012). Transport accessibility and social inequities: A tool for identification of mobility needs and evaluation of transport investments. Journal of Transport Geography, 24, 142-154. doi:10.1016/j.jtrangeo.2011.12.004

Brewer, C. A., \& Harrower, M. (2013). ColorBrewer2. Retrieved from http://colorbrewer2.org/

Bruinsma, F. R., \& Rietveld, P. (1998). The accessibility of European cities: Theoretical framework and comparison of approaches. Environment and Planning A, 30(3), 499-521. doi:10.1068/ a300499 
Curl, A., Nelson, J. D., \& Anable, J. (2011). Does accessibility planning address what matters? A review of current practice and practitioner perspectives. Research in Transportation Business and Management, 2, 3-11. doi:10.1016/j.rtbm.2011.07.001

De Bok, M., \& Van Oort, F. (2011). Agglomeration economies, accessibility and the spatial choice behavior of relocating firms. Journal of Transport and Land Use, 4(1), 5-24. doi:10.5198/jtlu. v4i1.144

Dean, B. (2004). Shortest paths in FIFO time-dependent networks: Theory and algorithms. Rapport technique. Boston: Massachusetts Institute of Technology (MIT). Retrieved from http://people. csail.mit.edu/bdean/tdsp.pdf

Deboosere, R., Levinson, D., \& El-Geneidy, A. M. (2017). Accessibility-oriented development. In 97th Transportation Research Board annual meeting (pp. 1-18). doi:10.1016/j. jtrangeo.2018.05.015

Dodson, J., \& Sipe, N. (2008). Shocking the suburbs: Urban location, homeownership and oil vulnerability in the Australian city. Housing Studies, 23(3), 377-401. doi:10.1080/02673030802015619

Eliasson, K., Lindgren, U., \& Westerlund, O. (2003). Geographical labour mobility: Migration or commuting? Regional Studies, 37(8), 827-837. doi:10.1080/0034340032000128749

EUROSTAT. (2014). Labour force. Retrieved from http://ec.europa. eu/eurostat/statistics-explained/index.php/Glossary:Labour_force

Geurs, K. T., \& Ritsema van Eck, J. (2001). Accessibility measures: Review and applications. Evaluation of accessibility impacts of land-use transportation scenarios, and related social and economic impact. Bilthoven. Retrieved from https://rivm.openrepository. $\mathrm{com} / \mathrm{rivm} / \mathrm{handle} / 10029 / 9487$

Geurs, K. T., \& Ritsema van Eck, J. (2003). Evaluation of accessibility impacts of land-use scenarios: The implications of job competition, land-use, and infrastructure developments for the Netherlands. Environment and Planning B: Planning and Design, 30(1), 69-87. doi:10.1068/b12940

Geurs, K. T., \& Van Wee, B. (2004). Accessibility evaluation of landuse and transport strategies: Review and research directions. Journal of Transport Geography, 12(2), 127-140. doi:10.1016/j. jtrangeo.2003.10.005

Handy, S. L., \& Niemeier, D. A. (1997). Measuring accessibility: An exploration of issues and alternatives. Environment and Planning A, 29(7), 1175-1194. doi:10.1068/a291175

Hansen, W. G. (1959). How accessibility shapes land use. Journal of the American Institute of Planners, 25(2), 73-76. doi:10.1080/ 01944365908978307

Haugen, K., Holm, E., Strömgren, M., Vilhelmson, B., \& Westin, K. (2012). Proximity, accessibility and choice: A matter of taste or condition? Papers in Regional Science, 91(1), 65-84. doi:10. 1111/j.1435-5957.2011.00374.x

Ingram, D. R. (1971). The concept of accessibility: A search for an operational form. Regional Studies, 5(2), 101-107. doi:10.1080/ 09595237100185131

Johansson, B., Klaesson, J., \& Olsson, M. (2002). Time distances and labor market integration. Papers in Regional Science, 81(3), 305327. doi:10.1007/s101100200000

Kwan, M.-P. (2013). Beyond space (as we knew it): toward temporally integrated geographies of segregation, health, and accessibility. Annals of the Association of American Geographers, 103(5), 1078-1086. doi:10.1080/00045608.2013.792177

Levine, J., Merlin, L., \& Grengs, J. (2017). Project-level accessibility analysis for land-use planning. Transport Policy, 53, 107-119. doi:10.1016/j.tranpol.2016.09.005

Levinson, D., Marion, B., Owen, A., \& Cui, M. (2017). The city is flatter: Changing patterns of job and labor access. Cities (London), 60, 124-138. doi:10.1016/j.cities.2016.08.002

Martínez, L. M., \& Viegas, J. M. (2013). A new approach to modelling distance-decay functions for accessibility assessment in transport studies. Journal of Transport Geography, 26, 87-96. doi:10.1016/j.jtrangeo.2012.08.018

Ministerie van Infrastructuur en Milieu. (2015). Publieksrapportage Rijkswegennet. 3e periode 2014. The Hague: Ministerie van Infrastructuur en Milieu. Retrieved from https://www. rijksoverheid.nl/documenten/rapporten/2015/02/12/ publieksrapportage-rijkswegennet

Morris, J. M., Dumble, P. L., \& Wigan, M. R. (1979). Accessibility indicators for transport planning. Transportation Research Part A: General, 13(2), 91-109. doi:10.1016/0191-2607(79)90012-8

Östh, J., Lyhagen, J., \& Reggiani, A. (2016). A new way of determining distance decay parameters in spatial interaction models with application to job accessibility analysis in Sweden. European Journal of Transport and Infrastructure Research, 16(2), 344-363.

Páez, A., Scott, D. M., \& Morency, C. (2012). Measuring accessibility: Positive and normative implementations of various accessibility indicators. Journal of Transport Geography, 25, 141-153. doi:10.1016/j.jtrangeo.2012.03.016

Reggiani, A. (1998). Accessibility, trade and location behaviour. Aldershot: Ashgate.

Reggiani, A., Bucci, P., Russo, G., Haas, A., \& Nijkamp, P. (2011). Regional labour markets and job accessibility in city network systems in Germany. Journal of Transport Geography, 19(4), 528536. doi:10.1016/j.jtrangeo.2010.05.008

Statistics Netherlands. (2011). Onderzoek Verplaatsingen in Nederland (OViN). Retrieved from https://www.cbs.n1/nl-nl/onzediensten/methoden/onderzoeksomschrijvingen/korteonderzoeksbeschrijvingen/onderzoek-verplaatsingen-innederland-ovin-

Statistics Netherlands. (2015). Kaart met statistieken per vierkant van 100 bij 100 meter. Retrieved from http://www.cbs.nl/nl-NL/ menu/themas/dossiers/nederland-regionaal/publicaties/ geografische-data/archief/2014/2013-kaart-vierkanten-art.htm

Statistics Netherlands. (2017a). Arbeidsdeelname; kerncijfers. Retrieved from https://opendata.cbs.nl/statline/\#/CBS/nl/dataset/ 82309NED/table?ts=1517507849657

Statistics Netherlands. (2017b). Number of unemployed drops below 400 thousand. Retrieved from https://www.cbs.nl/en-gb/news/ 2017/51/number-of-unemployed-drops-below-400-thousand

Statistics Netherlands. (2017c). Personenmobiliteit in Nederland; vervoerwijzen en reismotieven, regio's. Retrieved from https:// opendata.cbs.nl/statline/\#/CBS/nl/dataset/83500NED/table?ts= 1517506326106

Statistics Netherlands. (2017d). Verkeersprestaties motorvoertuigen; kilometers, voertuigsoort, grondgebied. Retrieved from https:// opendata.cbs.n1/statline/\#/CBS/n1/dataset/80302ned/table?ts= 1517507530633

Stichting LISA. (2016). Landelijk InformatieSysteem van Arbeidsplaatsen (LISA) 2009-2014. Retrieved from https:// www.lisa.nl/home

Sweet, M. N. (2011). Does traffic congestion slow the economy? Journal of Planning Literature, 26(4), 391-404. doi:10.1177/ 0885412211409754

Thorsen, I., Ubøe, J., \& Nævdal, G. (1999). A network approach to commuting. Journal of Regional Science, 39(1), 73-101. doi:10. 1111/1467-9787.00124

TomTom. (2013). Speed profiles. Retrieved from http://www.tomtom. com/en_gb/licensing/products/traffic/historical-traffic/speedprofiles/\#tab:tab1

Weber, J., \& Kwan, M.-P. (2002). Bringing time back in: A study on the influence of travel time variations and facility opening hours on individual accessibility. Professional Geographer, 54(2), 226240. doi:10.1111/0033-0124.00328

Weibull, J. W. (1976). An axiomatic approach to the measurement of accessibility. Regional Science and Urban Economics, 6, 357-379. doi:10.1016/0166-0462(76)90031-4 